\section{New electronic thesauri}

Linguistic Systems BV (Nijmegen, Netherlands) and Microlytics Inc. (East Rochester, NY, USA) are cooperating in the commercial development of a suite of multilingual reference works to be released both on diskette and as independent, handheld units.

The diskette-based versions will be called MultiTrans. Their handheld counterparts

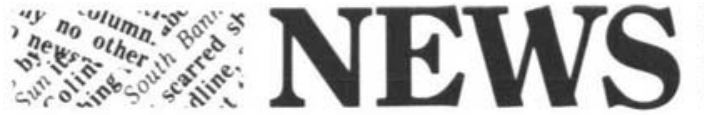

spellt uv persuli-ycals uevelupuis uicse cicetronic multilingual thesaurus-dictionaries. Five languages (English, French, Spanish, German and Dutch) are ready - a total of 20 language pairs. Six additional languages are in preparation: Italian, Japanese and the Scandinavian group.

The Nijmegen-based firm's managing director Leo Konst claims the thesaurusdictionaries are "unique tools for translators," in that they link not just words but also semantic clusters from language to language.

Not only, for example, will the English word "area" be translated in its various meanings ("surface area in square units," "location," "abstract domain," etc.) into the appropriate target language; synonyms of, and words related to, each of those translations will also be immediately accessible in both source and target languages.

Konst calls this approach "culturally sensitive". He adds: "The nature of semantic clusters vary enormously from language to language, and just as in any good bilingual reference work, the similarities and differences must be made clear to the user."

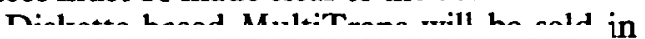
Mes). If thens of jingo- Telegrator in last noted "In In other wi ses Dily Star, "abling or long aphalmer tork tablol. Words will, ig es equally, "pispapel Sug one, New yith Rudoll sub-editors, Ig as separate language-pair consumer modules (US\$200).

Microlytics Inc. will market Multi-Trans. The East Rochester firm will also participate in the development of the handheld TR 300 .

Linguistic Systems BV, Keizer Kareplein 32-B, 6511 NH Nijmegen, The Netherlands. Tel: +31 (80) 540333 .

Microlytics Inc., 300 Main Street, East Rochester, NY 14445, USA.

Tel: +1 (716) 2489150 .

(From the Language Industry Survey, Press Bulletin 7, 1990)

\section{Electronic dictionaries galore}

Three American companies, Franklin, Proximity, and Houghton Mifflin have been selling electronic dictionaries at an astonishing rate.

Franklin Computers is collaborating with Rusky Yazyk Publishers (USSR) to develop the first handheld electronic bilingual Russian-English dictionary.

"This Russian-English bilingual dictionary is the most current and important dictionary approved in the USSR," said Morton E. David, Franklin's chairman and CEO.

Franklin has also signed an agreement with
Oxford Univeristy Press (UK) for the exclusive world rights to the newly released fourth edition of the Oxford Advanced Learner's Dictionary in handheld form.

Another Franklin agreement, this time with Collins Publishers (Scotland, UK), paves the way for the development of a series of Spanish-English, French-English, German-English, and Italian-English, handheld electronic dictionaries.

Meanwhile, Proximity Technology Inc., a Franklin subsidiary, has entered a licensing agreement with Aldus Corp., Claris Corp., Sun Microsystems, and Finland's Nokia Data Systems, enabling these companies to use Proximity's International Spelling Verification, Spelling Correction, and Hyphenation 
routines in 12 languages. From now on, product updates by these companies will include Proximity's linguistic software.

The Software Division of Houghton Mifflin, another very prominent player in the linguistic software market, has introduced the American Heritage Electronic Dictionary (AHED), an electronic version of the publisher's venerable dictionary of American English.

The AHED comes in three editions: a Comprehensive Edition; A Concise Edition; and a Compact Edition. The Comprehensive edition comprises definitions of 240,000 words.

In addition to proper spelling and definitions, the Comprehensive Edition supplies pronunciations, parts of speech, hyphenation points, synonym paragraphs, etymologies, usage notes, sample text and quotations, phrasal verbs ("blast off"), derived forms ("blatancy"), inflections ("think: thought, thinking, and thinks") as well as homographs.

A user can search for a (misspelled) word or for single or clusters of letters. Wildcard searchers are also supported, as well as Anagram searches ("beda" returns "abed, bade and bead").

The AHED is available for DOS, Macintosh, UNIX and VMS operating systems.

Franklin Computer, 122 Burrs Road, Mt. Holly, New Jersey 08060, USA.

Tel: $+1(609) 2614800$

Houghton Mifflin Software Division, One Memorial Drive, Cambridge, MA 02142, USA. Tel: + 1 (617) 2523000

(From the LIS, Press Bulletin 7, 1990)

\section{Doublespeak in the US}

The Harris Bank of Chicago has announced a program called "rightsizing the bank," which is described as "a program to substantially reduce its payroll costs through reducing head count." Currency Chronicle, Harris Bank Corporation, 28 February 1990.

- Fifteen employees at Clifford of Vermont, Inc. weren't laid off. "This was not a cutback nor a lay-off. It was a career-change opportunity," said Jim McNulty, president. Valley News (Conn.), 3 May 1990.

- Stouffer Foods Corporation did not lay off three hundred part-time workers. "These are called schedule adjustments, not layoffs," said Roz O'Hearn, public affairs manager, The Plain Dealer (Cleveland), 21 June 1990, p. 3-F.

Cray Research, Inc. is reducing its workforce through "voluntary termination," while IBM is asking for "voluntary resignations" from its "population." IEEE Spectrum, May 1990, p. 20.

- Workers are never laid off; they're "redundant," "excessed," "transitioned," or offered "voluntary severance." The Wall Street Fournal, 13 April 1990, p. B1.

- Eastman Kodak is selling a camera which comes loaded with a roll of film. Once you have taken all the pictures, you take the camera to a developer who develops the film and throws the camera away. Kodak does not call the camera "disposable" or "throwaway" - unacceptable terms in an age of increasing environmental awareness. Kodak calls it a "single-use" camera.

When Glad brought out a "biodegradable" plastic trash bag, Mobil Oil, the maker of Hefty trash bags, maintained that the plastic trash bag is impervious to degradation. But the sales of Glad trash bags went up while those of Hefty went down. So Mobil brought out its own "photodegradable" trash bag. Now the attorneys general of seven states have filed a lawsuit against Mobil Oil for claiming that its Hefty trash bags have a "special ingredient that promotes their breakdown after exposure to elements like sun, wind and rain." The Hefty boxes carry the claim that once nature has "triggered" this new additive, "these bags will continue to break down into harmless particles even after they are buried in a landfill." Mobil admitted that in its own tests it took 30 days in the sun of the Arizona desert for a bag to break down. In other less sunny climates, it takes about 120 days, and in a sunless landfill the bag won't break down at all. Said Mike Levy of Mobil, "Degradability is just a marketing tool." Opinion Week, 25 June 1990, p. 14.

"I have a negative net worth," said Bill Walters during hearings before the House Banking Committee. Walters had defaulted 